\title{
Embedding Economic Excellence: A Transformational Definition of “Corporate Governance” for Malaysia
}

\author{
Zulkifflee Mohamed, Garry James Clayton, Mohd Yaziz Mohd Isa \\ Universiti Tun Abdul Razak (UNIRAZAK), Kuala Lumpur, Malaysia
}

\begin{abstract}
The Malaysian government has carefully crafted policies to ensure that the nation achieves its aspirational goal to become a developed nation by 2020. Crucial for which is the success of the Securities Commission's "Corporate Governance Blueprint 2011” and “Capital Market Master Plan 2” designed to provide a business environment which attracts investment and talent. Somewhat overlooked in these otherwise robust policy shifts has been a critical critique of the definition, nature, and purpose of corporate governance itself. Recognizing this oversight, Tan Sri Muhyiddin Yassin, Malaysia's Deputy Prime Minister, has directed that the definition of corporate governance be rejuvenated for the 21st century. This paper looks to answer that challenge by recommending the following transformational definition for corporate governance: "the proactive implementation of accountable ethical processes, procedures, and policies that inspires innovative aspirational economic activity to produce sustainable wealth and prosperity for shareholders, stakeholders, and society”.
\end{abstract}

Keywords: corporate governance, Malaysian Code of Corporate Governance (MCCG), sustainability, Malaysia

\section{Introduction}

Over the last 15 years, the Malaysian economy, though challenged by a multiplicity of global financial crisis, has remained both stable and reliable in its performance. This robustness in the economy has been facilitated primarily by judicious governmental policy with respect to the development of a strengthened "Malaysian Code of Corporate Governance" (MCCG). Developed in response to the Asian Financial Crisis of the late 1990s, the MCCG incorporates the internationally recognized standards of best practice articulated by the Organization of Economic Cooperation and Development (OECD, 1999) as:

(1) Fairness;

(2) Transparency;

(3) Accountability;

(4) Responsibility.

The value of the MCCG is perhaps best illustrated by the confidence and trust it has engendered with international institutional investors and rating agencies, ensuring favorable terms and recognition for the

Zulkifflee Mohamed, associate professor and deputy dean, Bank Rakyat School of Business \& Entrepreneurship (BRSBE), Universiti Tun Abdul Razak (UNIRAZAK). Email: zulkifflee@unirazak.edu.my.

Garry James Clayton, professor and dean, Bank Rakyat School of Business \& Entrepreneurship (BRSBE), Universiti Tun Abdul Razak (UNIRAZAK).

Mohd Yaziz Mohd Isa, senior lecturer, Bank Rakyat School of Business \& Entrepreneurship (BRSBE), Universiti Tun Abdul Razak (UNIRAZAK). 
Malaysian economy. Its holistic and integrated approach of process, structure, and objective provides clarity of both principles and purposes for businesses.

The core of the MCCG is the seminal "Report on Corporate Governance" written by the Finance Committee on Corporate Governance (FCCG, 1999). It crafted a prescriptive guide of conduct that was based on a working definition it crafted and that is still currently used in Malaysia. The FCCG defined corporate governance as:

... The process and structure used to direct and manage the business and affairs of the company towards enhancing business prosperity and corporate accountability with the ultimate objective of realizing long-term shareholder value, whilst taking into account the interests of other stakeholders.

Underpinned by a strong and evolving regulatory framework, Malaysia's corporate governance system has been continuously improved since its inception through additional legislation, increased regulations, and the establishment of new facilitating agencies such as the "Minority Shareholder Watchdog Group" and the "Audit Oversight Board” (Securities Commission Malaysia [SCM], 2011a).

One unintended consequence of the internationally well-regarded regulatory regime has been an overemphasis by firms on compliance and risk management (Monsod, 2010; Muhyiddin Yassin, 2012). Though these are vital ingredients for quality corporate governance, they are insufficient for the economic transformation signaled by the Malaysian government's New Economic Models (NEM) and Economic Transformation Programme (ETP).

\section{Rejuvenating Malaysian Corporate Governance}

Recognizing the innate weakness embedded in the very strength of the current corporate governance regime, the SCM has ambitiously embarked on a project to rejuvenate the system. Establishing an "International Corporate Governance Consultative Committee" to provide strategic direction and advice, the Securities Commission has begun to craft a clear strategic direction for the enhancement of corporate governance in Malaysia. Two results from this endeavor have been the publication of "Corporate Governance Blueprint 2011: Towards Excellence in Corporate Governance" and the "Capital Market Master Plan 2" (themed "Growth with Governance"). In combination, they provide support for the quantum leap needed for the implementation of the "NEM" and the government plan to ensure that Malaysia's economy reaches a developed nation status by 2020. Excellent corporate governance ongoing contribution to the economic transformation will be continued access to funds from internationally influential investors who are constantly reviewing governance practices and development before deploying their capital. Access to such funds at reasonable rates will further foster a conducive business environment, especially for entrepreneurial and innovative economic activities viewed as critical to the future of the Malaysian economy (SCM, 2011a; 2011b).

What the Securities Commission did not undertake, however, was the equally important critical re-examination of the very concept and definition of corporate governance. This challenge has been raised by Tan Sri Muhyiddin Yassin, Malaysia’s Deputy Prime Minister, in the keynote address he presented to the 2012 Companies Commission National Conference in Kuala Lumpur. In a concise review of corporate governance practice in Malaysia, the Deputy Prime Minister highlighted the urgent need to transform the concept from being a tool to mitigate risks into a strategic 21st century mechanism to boost economic endeavor in an ethical manner. He foresaw that such a transformation would motivate employees, increase productivity, as well as become a magnate for investors and talent (Muhyiddin Yassin, 2012). 
The Deputy Prime Minister's challenge to transform the concept of corporate governance though daunting is demanded for the maturing Malaysian economy. Faced with a complex uncertain globally competitive world, Malaysian businesses need to be innovative enterprising incubators of sustainable wealth and prosperity. The paradigm shift this involves requires a critique of the nature of corporate governance, the context within which it operates, and its very purpose. Without such a review, the exercise of writing a new definition no matter how eloquently put would be at best a simple rehash of current thinking with perhaps moderate improvement and at worst a disconnected disorientating statement with the potential to undermine the trust currently enjoyed by the MCCG.

\section{Understanding the Concept of Corporate Governance}

At its most basic, corporate governance is about ensuring the sustainability of an organization. This generally is achieved by its maintaining its relevance, reliability, and reputation; the relevance to the market in terms of product or service offering, the reliability to investors with respect to accountable efficient utilization of resources; and its reputation for transparent ethical practices. As such, it is a dynamic evolving process instead of a stable state or final destination. It continually evolves to meet ever more complex challenges. Initially, corporate governance was concerned with little more than providing direction for the financial operations of individual companies. Over time, it has become an instrument for positive societal changes by first incorporating national and international best practices, then by expanding its focus from shareholders and stakeholders to the wider community (Claessens, 2003).

One significant change in the evolution of the essential nature of corporate governance has been it becoming an alignment instrument that looks to balance competing economic and social goals. Originally in terms of equity, this has evolved too and increasingly is inter-generationally, with corporate governance, looking to ensure that today's needs are not met at the expense of future generation's ability to meet their needs. Corporate governance is clearly a multifaceted complex integrated combination of plans, processes, and patterns of behavior designed to help organizations realize desired outcomes (Claessens, 2003).

Though its essential nature can be distilled and generally agreed to, corporate governance has no universally accepted business model. Jurisdiction, culture, and industry type have unique demands with respect to both form and purpose. This is further complicated by a multiplicity of competing theoretical models ranging from those focused on traditional structures to those emphasizing core competencies (Macnamara, 2005). Generically, the theoretical models can be classified into five categories representing five distinct approaches with respect to corporate governance:

(1) Structural (traditional): This approach emphasizes the importance of the legal entity. As such, it looks to define the board's processes and accountability through agreed policies and procedures;

(2) Policy (Carver): This approach was pioneered by John Carver and focuses on defining what the organization is trying to achieve and what policies it must create to expedite that;

(3) Outcomes (Cortex): This approach was developed by John Por as the "cortex model”. Like the policy model, its focus is on what the organization is doing but focuses on external influences such as legislation, industry best practice, and customer satisfaction;

(4) Process (Consensus): This approach focuses on decision-making, accountability, and competent board members; 
(5) Practices (Competency/skills): This approach focuses on continuous improvement looking constantly to enhance the skills and abilities of the board in order to improve decision-making.

While articulated separately with distinct characteristics, it is rare for any organization to utilize any theoretical model or approach to corporate governance in its entirety or singularly. Rather, the models tend to be combined with organizations selecting the elements best suited to their operational requirements. This reinforces the notion that corporate governance requires the capacity to incorporate plans, policies, processes, and practices simultaneously (Macnamara, 2005).

Reviewing the component parts that corporate governance represents and how they should be inter-related, it is suggestive that it is by nature a guiding formula for organizations to both influence and be influenced by their context and setting. Any definition, therefore, must reflect its component parts, their characteristics, and ultimate purpose. This can be described succinctly as that corporate governance is the sum total of an organization's tasks, purposes, and values. As a formula, it would be written as:

$$
C G=\sum(f+t+p) * E
$$

where:

$C G=$ Corporate governance;

$f=$ Form (structure/model(s));

$t=$ Task (activities/operations);

$p=$ Purpose (outcomes/end state);

$E=$ Ethics (values/principles).

Providing a guiding formula for understanding corporate governance is an important first step in improvement. It is, however, equally as important to understand the context within which the formula of corporate governance operates. The relationship that corporate governance operates in is worth reemphasizing, as it provides the foundations for trust within the market. As already stated, it consists of the framework set by laws, regulations, investor expectations, and an organization's own constitution together with the nation's history and culture overlaid by shareholder, stakeholder, and societal inter-relationships. Generically, these constituent parts can be classified into four distinct but related elements which somewhat echo the theoretical models of corporate governance:

(1) Attitudes: the ethical and principled underpinning-how enlightened is the chosen form of corporate governance;

(2) Attributes: the laws, regulations, responsibilities, and accountabilities that enable trust to be developed - the enablers of the corporate governance;

(3) Actions: how the organization operationalizes its strategy, from decision-making to evaluation- the way corporate governance engages in business;

(4) Alignment: the inter-relationship and balance sought among shareholders, stakeholders, and society-the way corporate governance is embedded in the community at large.

The inter-relationships of these four elements can further enhance and strengthen corporate governance or they can completely negate its effectiveness. At its best, the equal integration of all four provides a context for inspirational corporate governance. This is an enlightened context that incorporates current best OECD practices with an increased emphasis on ethical values, honor, integrity, and leadership (see Figure 1). All other combinations, while not necessarily bad, are somewhat lacking. 
Without:

(1) Attitude (Values): Corporate governance functions well at current OECD standard but is impeded, lacking an appropriate emphasis on ethical values;

(2) Attributes (Framework): Corporate governance is incapacitated, lacking an appropriate robust regulatory regime;

(3) Actions (Operationalization): Corporate governance is inept, lacking basic management oversight;

(4) Alignment (Shareholder/stakeholder/societal balance): Corporate government is imperious, lacking connection with its community.

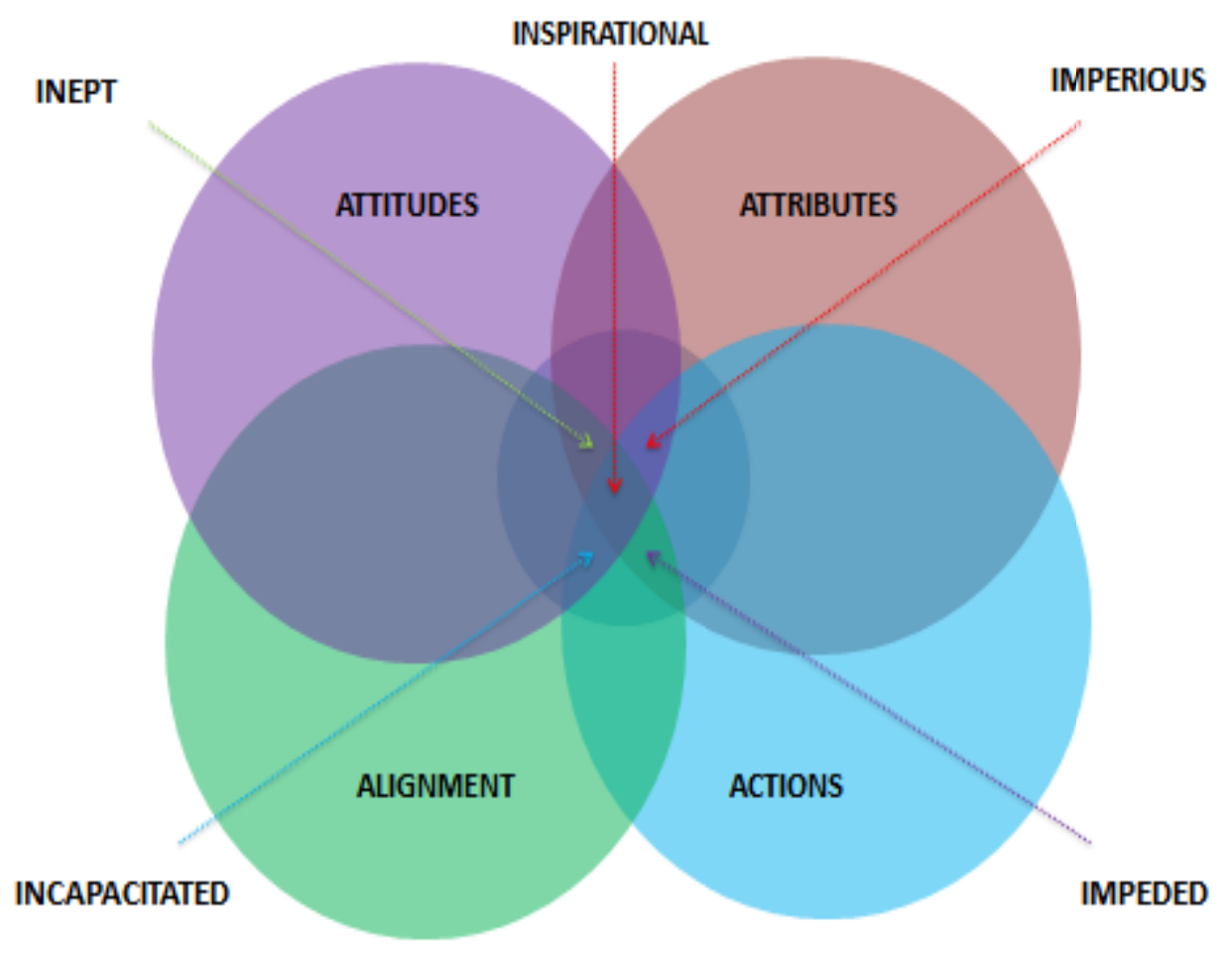

Figure 1. Contextual elements of corporate governance.

\section{Towards a New Malaysian Definition of Corporate Governance}

In crafting a new definition of corporate governance for Malaysia, it is necessary to do three things. First, it must build on existing strengths; there is little point in endangering a well-regarded reputation needlessly. Second, it must meet the four basic characteristics of form, task, and purpose underpinned by appropriate ethics and values. Finally, it needs to be inspirational, positioned at the juncture of the four contextual elements that corporate governance acts within.

The challenge of Tan Sri Muhyiddin Yassin is definitely daunting but is achievable. The proposed definition clearly must maintain the OECD standards of fairness, transparency, accountability, and responsibility. In addition, it needs to be ambitious, incorporating the desired shift from compliance management to compelling mission. It cannot ignore the importance of shareholder return, but it needs to do this from the perspective of the wider community at its aspirations. Finally, it must facilitate Malaysia's drive for a developed nation status by being aligned to the goals of the "NEM". 
While it is possible to write a vast number of permutations that would meet all the requirements for the new transformational definition of corporate governance for Malaysia, the following is perhaps the most succinct: the proactive implementation of accountable ethical processes, procedures, and policies that inspires innovative aspirational economic activity to produce sustainable wealth and prosperity for shareholders, stakeholders, and society.

\section{Conclusion}

Malaysia has an opportunity to move from simply imitation and innovation of other's best practice with respect to corporate governance to invention and trend setting by adopting a new transformational definition. Whatever the final word selected maybe, it is essential that they reflect the nature, form, purpose, and context that corporate governance operates in and for. It will need to retain existing internationally accepted standards but imbue then with a needed mix of both values and aspiration.

\section{References}

Claessens, S. (2003). Corporate governance and development. Washington: The International Bank for Reconstruction and Development/The World Bank.

Finance Committee on Corporate Governance [FCCG]. (1999). Report on corporate governance. Malaysia: Ministry of Finance.

Macnamara, D. (2005). Models of corporate/board governance. Leadership Acumen, Issue 21, pp. 1-10. Retrieved from http://www.banffexeclead.com/Newsletter04/PDF/Leadership\%20Acumen\%2021\%20V2\%20Models\%20of\%20Corporate \%20and\%20Board\%20Governance.pdf

Monsod, A. (2010). Evolution of corporate governance in Malaysia. Journal on Corporate Governance in Asia, 7(3), 20-22.

Muhyiddin Yassin, T. S. (2012). Keynote address. In SSM National Conference 2012 "Managing Corporate Governance. Creating Value. Transforming Economy”.

Organization for Economic Cooperation and Development [OECD]. (1999). Principles of corporate governance. Retrieved from http://www.oecd.org/corporate/oecdprinciplesofcorporategovernance.htm

Securities Commission Malaysia [SCM]. (2011a). Corporate governance blueprint 2011: Towards excellence in corporate governance. Retrieved from http://www.sc.com.my/wp-content/uploads/eng/html/cg/cg2011/pdf/cg_blueprint2011.pdf

Securities Commission Malaysia [SCM]. (2011b). Capital market master plan 2 (growth with governance). Retrieved from http://www.sc.com.my/post_archive/capital-market-masterplan-2-growth-with-governance/ 